\title{
Ésotérisme et littérature
}

\section{Christophe Didier}

\section{(2) OpenEdition}

Journals

Édition électronique

URL : https://journals.openedition.org/rbnu/3173

DOI : $10.4000 /$ rbnu.3173

ISSN : 2679-6104

\section{Éditeur}

Bibliothèque nationale et universitaire de Strasbourg

\section{Édition imprimée}

Date de publication : 1 novembre 2011

Pagination : 6-7

ISSN : 2109-2761

\section{Référence électronique}

Christophe Didier, «Ésotérisme et littérature », La Revue de la BNU [En ligne], 4 | 2011, mis en ligne le 01 novembre 2011, consulté le 08 août 2021. URL : http://journals.openedition.org/rbnu/3173 ; DOI : https://doi.org/10.4000/rbnu.3173

\section{(c) (i) (3)(2)}

La Revue de la BNU est mise à disposition selon les termes de la Licence Creative Commons Attribution - Pas d'Utilisation Commerciale - Partage dans les Mêmes Conditions 4.0 International. 


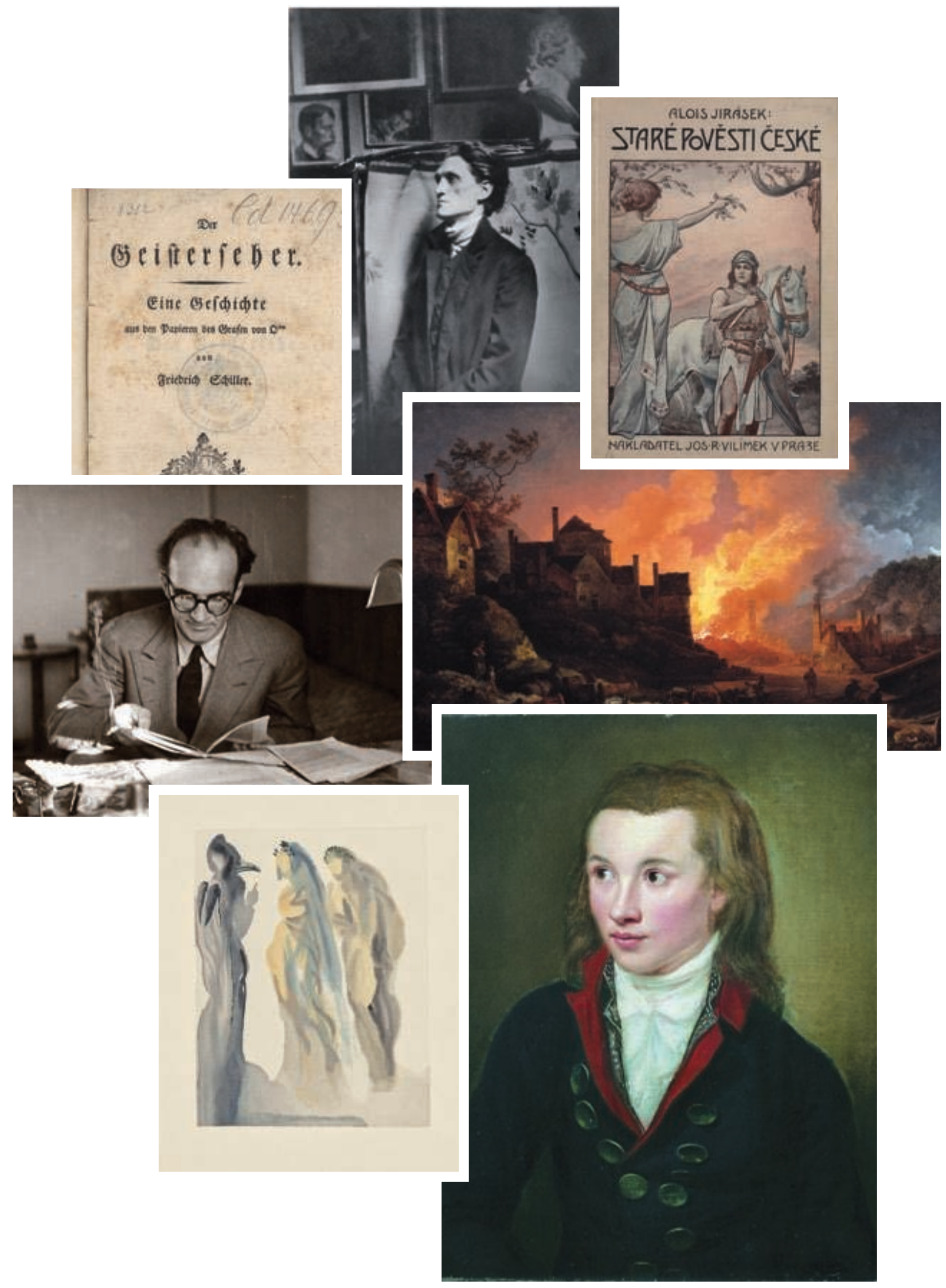




\section{LE DOSSIER Ésotérisme et littérature}

Ésotérisme et littérature : voilà une association qui demande à être discutée. Pour l'amateur de littérature, elle ne va pas de soi ; hormis quelques cas d'affinités indiscutables, l'ésotérisme est plutôt vu comme une source d'inspiration parmi d'autres, et non le moteur d'une pensée ou d'une écriture. Pour l'ésotériste en revanche, il n'y a pas de doute : les plus grands écrivains ont participé à cette quête, et leur œuvre est d'abord à comprendre à l'aune de celle-ci.

Tentons de définir l'ésotérisme : une somme d'enseignements secrets, immémoriaux mais perdus pour la plupart, vérités fondamentales demeurées toujours les mêmes à travers les âges et que seuls des initiés ont transmises, et continuent à transmettre à ceux qui sont dignes de les recevoir et les transmettront à leur tour. Mais comment opérer la transmission de cette " gnose ", de cette connaissance intuitive supra-rationnelle et transcendante par nature à toute formulation verbale et discursive ? Car il faut bien trouver, malgré tout, comment mettre en mots l'inexprimable et c'est ainsi qu'on a pu dire que l'enseignement ésotérique revêtait presque fatalement une forme symbolique, à la recherche des correspondances permettant de rendre perceptibles des vérités que le seul langage serait incapable de formuler.

Dans cette optique, quel plus beau matériau que la création littéraire, ses mythes, ses légendes qui se répondent d'une époque à l'autre et offrent ce " théâtre de miroirs " où l'ésotériste entrevoit autant de reflets de l'invisible ? Et c'est ainsi qu'il convoque des noms aussi divers que Dante, Goethe, Blake, Novalis, Nerval, Yeats, Meyrink, Artaud ou Pessoa... L'attirance est bien sûr réciproque : la quête ésotérique et ses variantes occultes, théosophiques ou maçonniques a ses héros, ses martyrs et fournit à l'écrivain un vaste champ d'inspiration. Elle a aussi - osons le mot - son folklore que le souvenir de personnalités comme Péladan ou de Guaïta maintient aujourd'hui encore bien vivant. Elle touche enfin à une forme de révélation de soi-même et de son " être au monde " que plus d'un poète a placée au cœur de sa création.

Que l'écrivain soit souvent tenté d'utiliser un matériau ésotérique est donc incontestable; les pages qui suivent en montreront quelques avatars. Ce matériau reste l'ingrédient, anecdotique parfois, mais souvent paradoxalement fertile, d'un but littéraire ou artistique : c'est ce qui ressort de la plupart des analyses. L'ésotérisme en littérature est rarement une fin en soi. La recherche d'une vérité fondamentale peut bien être au cœur de mainte construction poétique ou romanesque, elle n'en demeure pas moins celle de l'écrivain lui-même, celle du sens à donner à son œuvre ou à sa quête. Seuls les ésotéristes convaincus y voient un sens universel qui existerait de toute éternité et prendrait les détours d'une fiction pour se révéler. Pour eux, la littérature ne fait qu'exprimer une vérité qui lui serait extérieure, se mettant en quelque sorte " à l'épreuve de l'occulte " : c'est ce que le dossier rappellera aussi. Mais pour la plupart des écrivains, l'objet littéraire n'est pas soluble dans l'ésotérisme : il est au contraire un appel récurrent à le dépasser.

\section{Christophe Didier}

